four thugs, and having had a chair broken over his head at three o'clock in the morning, is back at work functioning efficiently by about 9 a.m. ? The only logical explanation is that being beaten unconscious really does very little harm to anyone.

Let us have less violence and a more realistic presentation of the after-effects of trauma - I am, etc.,

\section{Philip Banister.}

Child and Maternal Health Division,

Deprtment of National Health and Welfare
Ottawa 3, Ontario, Canada.

\section{Subnormal Hospitals}

SIR,-Dr. J. Gibson (6 September, p. 592) states that your description of conditions in subnormal hospitals (23 August, p. 426) is inaccurate or exaggerated. He stresses the advances in the treatment of the mentally retarded in this country, especially in "the good hospital " where "a lot" has been done "in spite of indifference in the old Ministry of Health ...." etc.

May I submit with all due respect for Dr. Gibson's undoubted good intentions that his comments are more likely to do harm than good? So long as people keep saying that things are not as bad as the critics suggest there is a danger that public and Ministerial (or Departmental) apathy and indifference will persist, reinforced by the comforting thought that the good hospitals will continue to manage in spite of increasing difficulties, and that it is up to the "bad hospitals" to make the same efforts as the good ones. That mental subnormality hospitals in foreign countries are even worse off than their British counterparts may be true, but it is a poor consolation indeed.

Surely by now everybody connected with the services for the mentally subnormal must know that gross overcrowding, insanitary conditions, understaffing, and hopelessly - long waiting-lists for admission are evils that affect practically every hospital and region? The sooner the medical profession as a whole and the public at large are made aware of this situation the greater the chances will be of more resources being allocated to the solution of this neglected problem.-I am, etc.,

\section{Leybourne Grange Hospital,}

\section{Arenillas.}

Sir,- You do well to give editorial attention (23 August, p. 426) to "sorrows that have befallen our hospitals for the mentally disordered," and to the dangers of damaging staff morale by unjustified suspicion of their professional integrity. If the revolution is at hand in which the "human warehouse," to use Dr. J. T. R. Bavin's telling phrase (23 August, p. 470), will become a serious form of social, including financial, reforming interest, no one would welcome it more than I, but if in this one seeks to identify the negligent one must beware of merely identifying the scapegoat, the symbol of society's guilt for past years of comparative disregard. Not only individuals but hospital management committees, hospital boards, and Ministries can be identified-and the more easily the less is known of the objective situation and its objective difficulties.
The press and other mass media have the major responsibility of keeping the community well informed, but share an addiction for the sensational which of ten almost, and sometimes wholly, negates the potential value of their revelations and commentaries. Certainly this hardly encourages responsible hospital staff to seek publicity for adverse conditions-and how, anyway, could they do this and yet maintain a reasonably loyal relationship with employing authorities who, at a different level, may well be involved in a parallel set of difficulties?

I entirely disagree with the appointment of "commissioners on the lines of the late Board of Control," and I think the suggestion casts an invidious shadow on many medical, nursing, and administrative colleagues who have long been struggling to achieve more humane conditions in long-stay hospitals within our semi-civilized British national culture. I also view with reserve your comments on the limitations of overseas staff, and I must emphasize that at the hospital with which I am personally principally associated doctors and nurses from other countries have made a very highly valued contribution.

In the last resort the community gets the psychiatric service it deserves, and one must hope that in reaching a decision on the many changes yet required it will not hazard the advances so relatively recently and laboriously gained or regained.-I am, etc.,

\section{Morgannwg Hospital,}

K. S. JONES.

Bridgend, Glam.

\section{An Explanation for Addiction}

SIR,-Dr. D. B. James offers "An Explanation for Addiction" (5 July, p. 53). If Dr. James wants to consider "mood" as a cause of addiction, the "mood" could be termed "the mood of facing reality."

The normal patient desires opiates to escape the reality of suffering. The addict desires opiates or psychotropic drugs to escape the reality of his life.

In effect, the addict is an escapist. Because of his technique of escape, he is potentially dangerous to society. We can laugh, or cry, at the escape techniques used by $\mathrm{Mr}$. Facey Romford, "Soapey Sponge," or the Great Gatsby. On a mundane level, the man who will not balance his accounts is an escapist. It is difficult to label a nation and its inhabitants when they do not wish to face reality and balance their accounts. The mass immigration of physicians from the United Kingdom is probably a reflection that a large number of physicians wish to face reality and do not desire a "opiate," be it a pharmaceutical or a sugar-coated fiat of the Government or its officials practising their "divine right" (5 July, p. 58).-I am, etc.,

New York, U.S.A.

JOHN B. STETSON.

\section{Awareness during Anaesthesia}

SIR,-In reply to Dr. G. M. Wyant (30 August, p. 532) we would quote from our original article (1 February, p. 280), “It should surely be our objective to provide not only a still and uncomplaining patient during anaesthesia, but also one who regards the past experience with no displeasure and the future anaesthetic with no apprehension." Thus it may be seen that our aims are the same as those of Dr. Wyant. Where we would disagree is the means whereby these aims may be attained.

Regional analgesia is certainly one method whereby unpleasant recall can be avoided, but this has two major drawbacks: (1) Some patients refuse to accept this as an alternative to general anaesthesia ; and (2) even in the most expert hands epidural analgesia is less than $100 \%$ certain, and in most departments where obstetric anaesthesia is carried out by anaesthetists still in training the degree of success obtainable makes this form of anaesthesia unacceptable for routine emergency use.

This then leaves the suggestion by $\mathrm{Dr}$. Wyant that " modern inhalation anaesthetic drugs in small doses supplemental to nitrous oxide are not so harmful. ..." Here is where we would definitely disagree with $\mathrm{Dr}$. Wyant, and would quote the extensive review of possible techniques given in Dr. J. S. Crawford's textbook. ${ }^{1}$ From the evidence here quoted, and otherwise generally accepted, the safest method of anaesthesia for the general good of both mother and child is a nitrous oxide/oxygen and relaxant technique. What we and others (22 February, p. 508) are currently trying to do is make this technique not only safe but also entirely free from the risk of recall.-We are, etc.,

\section{JAMES WILSON}

DAVID J. TURner.

Department of Anaesthetics, Royal Infirmary
Edinburgh 3 .

\section{REFERENCE}

Crawford, J., S., Principles and Practice
Obstetric Anaesthesia, 1965, 2nd ed. Oxford.

\section{Myoedema and Vitamins}

SIR,-This communication is prompted by the recent letter of Dr. L. L. Griffiths (2 August, p. 299) associating myoedema with vitamin $B_{1}$ deficiency.

Myoedema is an idiomuscular contraction, which is not associated with propagation of an electrical impulse, as determined by an electromyographical examination, which reveals an accompanying electrical silence. ${ }^{12}$ When a superficially placed muscle is directly stimulated by pinching, plucking, or percussion, a transient hillock or mound is formed within the muscle substance. The magnitude as well as the duration of this phenomenon is quite variable, depending upon the thickness of the soft tissues and the intensity and frequency of the blow delivered. Repeated testing commonly leads to exhaustion of this phenomenon.

Over the decades myoedema has been variously ascribed to pulmonary tuberculosis, cachexia, malnutrition, ${ }^{3}$ hyporitaminosis, ${ }^{3}$ hypothyroidism, ${ }^{4}$ and hypoalbuminaemia. ${ }^{5}$ This wide discrepancy is probably due to the varied methods of elicitation, the several different parameters used in considering an abnormal response, and the unbridled enthusiasm of different workers attempting to correlate the occurrence of myoedema to specific pathological or biochemical states.

However, as shown by the classic study of Jones and Parkes, ${ }^{6}$ and since confirmed by 
us, ${ }^{2}$ the most significant factor affecting the production of myoedema is the thickness of the muscle and the overlying soft tissues rather than the underlying disease state. Owing to the unpredictability of this sign, and the wide range of normality, it is doubtful whether it can ever be utilized as a reliable or useful bedside sign.-I am, etc.,

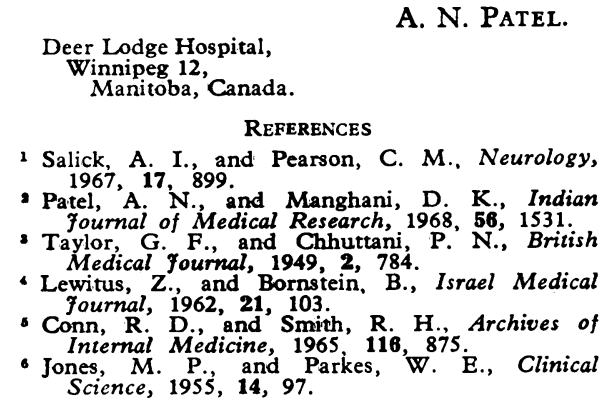

\section{Trimethoprim for Malaria}

SIR,-Your excellent note on trimethoprim in Today's Drugs (6 September, p. 578) omitted mentioning the value of this compound for treatment of $P$. falciparum infections resistant to 4-aminoquinolines (chloroquine and amodiaquine).

A report by Martin and Arnold ${ }^{1}$ indicated that trimethoprim in combination with sulfalene (3-methoxy-2-sulfanilamidopyrazine) can cure falciparum malaria in man. Both drugs are antagonistic in the synthesis and metabolism of folic acid, and have a potentiating or at least an additive effect on the dihydrofolate reductase. ${ }^{2}$

Experimental work on the simian $P$. knowlesi malaria indicates the mode of action of this drug combination. ${ }^{3}$ It is interesting that trimethoprim alone is relatively ineffective against acute infections of $P$. berghei in mice or $P$. knowlesi in rhesus monkeys while rather more effective against the human $P$. falciparum.-I am, etc.,

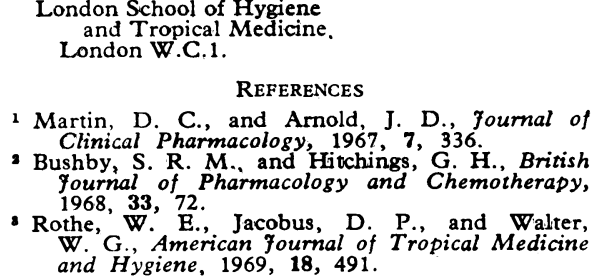

\section{Extra-articular Manifestations of Rheumatoid Arthritis}

SIR,-Dr. A. Calin is quite right (6 September, p. 598). Anaemia is certainly a very common manifestation of rheumatoid arthritis. It is so common, however, and has such a large literature devoted to it that I did not discuss it, as in the limited time of a college lecture-one hour-deletions have to be made in any large subject. Other extraarticular manifestations are those arising from bursae, tendons, bones, and mental states such as depression and anxiety, all of which contribute to, and play a part in, rheumatoid disease, and none of which did I attempt to discuss for the same reason.

Haematological features are well recognized in rheumatoid arthritis, and the changes of Felty's disease, for instance, are discussed in all comprehensive textbooks of haematology. From the Edinburgh unit alone a large amount of excellent work has emerged in the last few years on the nature of anaemia in rheumatoid arthritis. ${ }^{1}$ For this reason, particularly, I did not discuss it, as it had already been so fully discussed, but Dr. Calin is very right in drawing attention to its frequency and its importance, particularly in relation to therapy.

The extra-articular manifestations of rheumatoid arthritis comprise such a large subject that one could readily do another hour's lecture-a Part II, as it were-on the same theme, without re-covering any ground covered by the previous one.-I am, etc.,

\section{Westminster Hospital,}

\section{F. Dudley Hart.}

\section{REFERENCE}

1 Mowat, A. G., Hothersall, T. E., and Aitchison, 1969, 28, 303.

Sir,-Dr. A. Calin (6 September, p. 598) is hardly fair to Dr. F. Dudley Hart (19 July, p. 131) in expecting him to discuss the very complex problem of the anaemia of rheumatoid arthritis in his Philip Ellman lecture. The anaemia associated with this condition is so common that it hardly merits consideration alongside the rarer extra-articular manifestations of the disease which were the subject of this lecture. In addition, Dr. Calin is less than fair to a large number of investigators when he says "very little is known about the aetiology of this anaemia." In particular, since 1955 a succession of workers in the Rheumatic Diseases Unit, Northern General Hospital, Edinburgh, have published over a dozen papers on various aspects of iron metabolism and the normocytic, hypochromic anaemia in rheumatoid arthritis, quite apart from several contributions to the understanding of the associated but less common megaloblastic anaemia. Most of these papers have appeared in the Annals of the Rheumatic Diseases, and the present state of our knowledge has been summarized. ${ }^{1}$

The mechanisms involved in the causation of this anaemia are numerous. Minor factors are a mild impairment in the absorption of iron from the gastrointestinal tract; a mild extra-corpuscular haemolysis; a small increase in plasma volume; a failure of the bone marrow to increase red cell production above normal levels because of reduced erythropoietin activity whether due to a failure of production or the presence of an inhibitor or antibody; that in the presence of a low serum albumin the incorporation of iron into new erythrocytes is impaired; an increased rate of degradation of transferrin, and a diminished release of endogenous iron from senescent red cells. The importance of blood loss from the gastrointestinal tract induced by salicylate and other drug therapy as a cause of the anaemia has been exaggerated. ${ }^{2}{ }^{3}$

The major factor in the aetiology of this anaemia is the increased uptake and failure of release of iron by the hyperplastic reticulo- endothelial system and the phagocytic cells of the proliferated synovial tissue. Calculations suggest that as much as $800 \mathrm{mg}$. of iron may be stored in the synovial tissue of a patient with active rheumatoid arthritis

Most of these abnormalities of iron metabolism are well correlated with the activity of the discase. Indeed, it has been postulated that the serum iron value is the best indicator of disease activity. ${ }^{45}$ Thus if the disease is controlled the hypochromic, normocytic anaemia can be corrected without the addition of any haematinic. ${ }^{5}$ Correction also may be achieved if large quantities of parenteral iron are administered, as, unlike oral therapy, this allows sufficient iron for new erythrocyte production to bypass the overactive reticuloendothelial system and synovial tissue. The best results are achieved when a combination of these methods is used. ${ }^{6}-\mathrm{I}$ am, etc.,

Alastair G. Mowat.

\section{RERERENCES}

1 Mowat, A. G., and Hothersall, T. B., Annals of the Rheumatic Diseases, $1968,27,345$.

3 Baragar F D. Gut, 1968, 9, 475. Medical fournal 1960, 1 , 106 .

Whittingham, S., Balazs, N. D. H., and Mackay, I. R., Medical fournal of Australia, 1967, 2, Mowat, A. G., Hothersall, T. E., and Aitchison, W. R. C., Annals of the Rheumatic Diseases,

Duthie, J.' J. R., Scottish Medical Fournal, 1967,
12, 96.

\section{G.M.C.'s Annual Levy}

SIR,-Although I have been a member of B.M.A. for the last four years, unfortunately I failed to take note of the subject of a leading article in the B.M.f. (3 May, p. 266) and correspondence and reports of meetings, all purporting to inform the like of us the news of a new "levy" on the profession. I, of course, refer to the decision of the General Medical Council to charge members of the profession an annual fee for the privilege of being on the Register. This came to me as an unexpected blow, and many of my colleagues seemed to react with a similar sense of surprise and unawareness. But the surprise turned into a feeling of frustration and betrayal when it was learnt that B.M.A. had negotiated with G.M.C. (from 1965 when the subject was first brought up), and agreed acceptance on behalf of the profession of an annual retention fee, the amount of which is to be determined.

Already I find it difficult to understand the logic of the annual taxes that one has to offer to the royal colleges (heaven help you if you are a Fellow or member of more than one college !). However, it may still be argued in their favour that they are offering a continuing service in the form of refresher courses, regional lectures and demonstrations (although not always free), and also facilities (library, etc.) on the college premises. But can one clearly define the kind of services the G.M.C. is going to provide which would require adding to its present annual income of $£ 145,000$ an estimated $£ 130,000$ to $£ 195,000$ per year, if each of Britain's 65,000 doctors are charged $£ 2$ to $£ 3$ per year?

But of course we must face realities. The G.M.C. is not a profit-making body, and if it needs money it has got to have it. However, I don't agree that the State should not be asked to provide the grants to this indepen- 